See Article page 69.

\section{Commentary: The immunologic mystery of cardiac myxoma}

\author{
Ali Al-Ameri, MD, and Tomas A. Salerno, MD
}

Myxoma is both a rare tumor and the most common cardiac tumor, with an annual incidence 0.5 to 1 new case per million individuals. ${ }^{1}$ It has female predominance, with a sex ratio of 3:1, and is classified into 2 main epidemiologic forms: the familial and the sporadic. ${ }^{1}$ Myxoma arises from the endocardial structures located mainly in the fossa ovalis, and it occurs more commonly on the left atrial side. ${ }^{1}$ Histologically, myxoma is composed of mesenchymal cell set in mucopolysaccharide stroma, immunohistochemically positive for CD31 and CD34 (endothelial markers) and for CD56 (immune cells marker, for example of natural killer cells and monocytes). ${ }^{2}$ Symptoms are mainly obstructive in nature, depending on size and location, or may arise from embolic events when the tumor is friable. Constitutional symptoms are reported to be more common in women who have cardiac myxoma than in men, and the tumor occurs mostly on the right side of the heart, for unknown reasons. Symptoms include malaise, anorexia, fever, arthralgia, and weight loss, and they often mimic connective tissue disorders. Usually erythrocyte sedimentation rate and C-reactive protein are elevated. ${ }^{3}$ Symptoms are attributed to the release of interleukin 6 (IL-6), which facilitates cell proliferation and differentiation, as well as to the release of acute phase reactants during inflammation. Cultured myxoma cells from patients with those symptoms have shown elevated levels of messenger RNA specific for IL-6. ${ }^{2}$ Diagnosis is usually made by echocardiography and magnetic resonance imaging, and treatment is by surgical excision of the tumor. Cardiac myxoma can recur, and elevated circulating levels of IL-6 are observed in this circumstance. $^{4}$

\footnotetext{
From the Division of Cardiothoracic Surgery, University of Miami Miller School of Medicine and Jackson Memorial Hospital, Miami, Fla.

Disclosures: Authors have nothing to disclose with regard to commercial support. Received for publication Dec 12, 2019; revisions received Dec 12, 2019; accepted for publication Jan 3, 2020; available ahead of print Feb 5, 2020.

Address for reprints: Tomas A. Salerno, MD, University of Miami Miller School of Medicine and Jackson Memorial Hospital, Miami, FL 33136 (E-mail: tsalerno@ med.miami.edu).

JTCVS Techniques 2020;1:73-4

2666-2507

Copyright (c) 2020 The Author(s). Published by Elsevier Inc. on behalf of The American Association for Thoracic Surgery This is an open access article under the CC BYNC-ND license (http://creativecommons.org/licenses/by-nc-nd/4.0/).

https://doi.org/10.1016/j.xjtc.2020.01.012
}

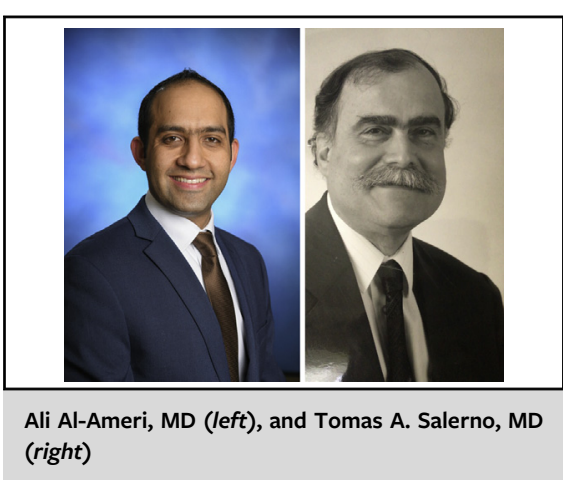

CENTRAL MESSAGE

A patient with cardiac myxoma presented with peripheral neutrophilic dermatosis. The immunologic aspects of this tumor are presented, with a review of its immunologic behavior.

The article by Ajiro and colleagues ${ }^{5}$ in this issue of the Journal reports the case of a patient with cardiac myxoma with granulocyte colony-stimulating factor, interleukin $1 \beta$ - and IL-6-positive myxoma cells associated with neutrophilic dermatosis. In the pediatric literature, Macias and colleagues ${ }^{6}$ reported the case of a 13-year-old healthy girl who had constitutional symptoms and lower extremity purpuric rash and was found to have a cardiac myxoma. Symptoms and rash resolved after resection. More recent immunologic studies have suggested expression of multiple macrophage phenotypes with release of different inflammatory mediators, such as tumor necrosis factor $\alpha$. This might be related to mechanical stress caused by the mass in the atrial cavity. These responses directly correlate with the size of the tumor, being more pronounced when the tumor is large, and are the reason that constitutional symptoms occur. ${ }^{3}$ It is not, therefore, a surprise to see multiple cytokines and factors such as with neutrophilic dermatosis in a such an immunologically active tumor.

We believe that the article by Ajiro and colleagues ${ }^{5}$ shines a light again on this rare entity. Prolonged time elapsed from the onset of noncardiac symptoms until the diagnosis of myxoma was made. The fact that this tumor probably had been present in the heart for many years (possibly a decade) and that symptoms only developed late, when the tumor was very large, suggests that tumor necrosis may account for the 
peripheral lesions. This finding emphasizes the importance of including cardiac myxoma in early differential diagnosis of patients presenting with purpuric rash and systemic symptoms. It is possible that in the future modulation of macrophage activation state in cardiac myxoma may become an important target for therapy.

\section{References}

1. Boutayeb A, Mahfoudi L, Moughil S. Atrial myxoma: from diagnosis to management. Clin Surg. 2017;2:1498.
2. Di Vito A, Santise G, Mignogna C, Chiefari E, Cardillo G, Presta I, et al. Innate immunity in cardiac myxoma and its pathological and clinical correlations. Innate Immun. 2018;24:47-53.

3. Thyagarajan B, Kumar P, Patel S, Agrawal A. Extracardiac manifestations of atrial myxoma. J Saudi Heart Assoc. 2016;29:37-43.

4. Maze Y, Kajimoto M, Tenpaku H, Satou T. Left atrial myxoma with sever inflammatory response. Jpn J Thorac Cardiovasc Surg. 2004;52:221-3.

5. Ajiro Y, et al. Granulocyte-colony stimulating factor-and interleukin-1ß positive cardiac myxoma accompanying neutrophilic dermatosis. J Thorac Cardiovasc Surg Tech. 2020;1:69-71.

6. Macias E, Nieman E, Yomogida K, Petrucci O, Javiadan C, Baszis K, et al. Rare presentation of an atrial myxoma in an adolescent patient. BMC Pediatr. 2018;18: 373. 